\title{
PUESTA AL DÍA Y NUEVAS REFLEXIONES SOBRE EL LIBRO Y SU EDITOR Y EL EDITOR Y SU LIBRO EN EL SIGLO XVI
}

\author{
Manuel José Pedraza Gracia* \\ Universidad de Zaragoza
}

\begin{abstract}
Resumen: Se analiza la figura del editor en el siglo xvi desde la perspectiva de las actuaciones que realiza en su labor. Para ello, en primer lugar, se presenta su figura dentro del proceso editorial de la época; en segundo lugar, se analiza su actividad en ese proceso. Este análisis se realiza a partir de documentación conservada desde tres perspectivas: económica, técnica y jurídica. Se concluye que la intervención del editor en el proceso de producción del libro es mucho más importante de lo que hasta el momento se ha pensado. En consecuencia, el editor tiene más responsabilidad sobre la morfología y el aspecto del libro que lo que se creía. Por tanto, es preciso profundizar en los estudios sobre el editor para definir su grado de participación a la hora de elaborar una determinada edición.

Palabras clave: Edición; editor; libro antiguo; siglo xvi; contratos de impresión.
\end{abstract}

Title: UPDATE AND NEW THOUGHTS ON THE BOOK AND ITS PUBLISHER, THE PUBLISHER AND HIS BOOK IN THE SIXTEENTH CENTURY.

Abstract: The figure of the publisher in the 16th century is analysed from the perspective of the actions he carries out in his work. In order to do this, firstly, his figure is presented within the editorial process of the time; secondly, his activity in that process is analysed. This analysis is based on documentation preserved from three perspectives: economic, technical and legal. It is concluded that the intervention of the publisher in the process of producing the book is much more important than has been thought so far. Consequently, the publisher has more responsibility for the morphology and appearance of the book than was previously thought. It is therefore necessary to study the publisher in greater depth, in order to define the degree of participation in the production of a given edition.

Keywords: Edition; publisher; rare book; 16th century; printing contracts.

Copyright: (C) 2019 Servicio de Publicaciones de la Universidad de Murcia (Spain). Este es un artículo de acceso abierto distribuido bajo los términos de la licencia Creative Commons Reconocimiento 4.0 Internacional (CC BY 4.0).

\section{INTRODUCCIÓN}

Por mucho que la elaboración de los libros en el Antiguo Régimen Tipográfico se pueda interpretar, entre otros, desde el punto de vista de sus tres figuras esenciales: autor, impresor y editor: el autor que «inventa» la obra, el impresor (o el taller) que «construye» con esa obra una edición (múltiples ejemplares) y el editor que, a tenor de las definiciones existentes, costea este proceso, la impresión que proporcionan los estudios realizados es que esta labor se ha llevado a cabo con una perspectiva más fundamentada en la realidad actual que en la situación real del momento de referencia.

\section{AUTOR, IMPRESOR, EDITOR... O VICEVERSA}

La investigación sobre la historia del libro, especialmente la que se ha preocupado del libro del Renacimiento y la Edad Moderna, se ha centrado de forma principal en la figura del impresor; y, en efecto, aunque todavía sea factible encontrar lagunas (algunas muy notables), las líneas gruesas de la historia de la imprenta sensu stricto son las mejor perfiladas y permiten, por sí solas, apreciar un panorama bastante completo conformándose como el segmento de la historia del libro hispano más desarrollado. Estos estudios derivan, con seguridad, de dos fenómenos que se desarrollaron en la decimonovena centuria, aunque alguno se puede remontar al siglo anterior y ambos culminen en el vigésimo, por orden cronológico: la persecución de la primacía en la erección de la primera imprenta hispana y las controversias sobre la misma ya planteadas en 1796 por Méndez (Odriozola, 1982) y la elaboración de tipobibliografías favorecidas por el acicate de los premios de la Biblioteca Nacional de España (Delgado, 2001).

Por lo que respecta al autor las diversas ciencias que se han dedicado a tratar su figura y sus obras profundizan en su relación con la producción del libro en muy escasas ocasiones, centrándose, como es lógico, en la obra y el personaje.

*pedraza@unizar.es

Recibido: 04-01-2019; $2^{\text {a }}$ versión: 29-01-2019; aceptado: 06-02-2019.

PEDRAZA GRACIA, M.J. Puesta al día y nuevas reflexiones sobre el libro y su editor y el editor y su libro en el siglo XVI. Anales de Documentación, 2019, vol. 22, $\mathrm{n}^{\mathrm{o}}$ 1. Disponible en: http://dx.doi.org/10.6018/analesdoc.22.1.356811. 
Son también escasos los trabajos de investigación dedicados a los editores que son finalmente los responsables de que esas obras viesen la luz en letras de molde. El primero que se plantea la función del editor en el proceso productivo del libro fue González de Amezúa en 1946. Jaime Moll (2003, p. 77) advirtió, un tiempo después, que «para que un texto llegue impreso a una librería, es necesaria la actuación conjunta e interrelacionada de tres factores: la industria editorial, la industria gráfica y el sector comercial». De esta manera Moll ponía de manifiesto que para comprender bien el fenómeno del libro impreso, además de la historia de la imprenta, había que dedicar también esfuerzos de investigación a la historia de la edición y a la historia de la librería, aspecto este que también requiere trabajos específicos.

Se hace necesario acudir a las fuentes documentales para apreciar las finas líneas que delimitan las actividades de esas tres industrias que en sus inicios no siempre mantuvieron límites perfectamente delimitados y estáticos. Esta situación ofrece un panorama complejo en el que solo se ha profundizado, en la mayoría de las ocasiones, desde una perspectiva teórica y desde el producto impreso. Pero la producción del libro (como relación comercial para elaborar conjuntos de objetos aparentemente idénticos con la intención de su comercialización) requiere una revisión desde la documentación que esta relación genera puesto que en ella se pueden encontrar el conjunto de aspectos que definen las relaciones entre las partes que intervienen en la producción del libro.

No es extraña la indiferencia por el editor, a pesar de la transcendencia de su actividad, ya que ni siquiera la legislación contemporánea responsabilizaba al editor del libro poniendo sus ojos casi de forma exclusiva en el fabricante de la obra encargada, el impresor. Sirva como ejemplo la pragmática de 7 de septiembre de 1558 en la que nada se dice de aquellos que costean la edición, aunque, por el contrario, transforme en preceptiva la mención del nombre del autor y del impresor (Reyes, 2000). Pero es que ni siquiera el propio término existe como tal y no se incluye en el Diccionario de la Academia Española hasta mediados de la década de los ochenta del siglo xix. Esta situación ha creado la especie (más difundida de lo que parece) de que el mundo editorial no surge hasta ese siglo (el xix) y que lo que podría identificarse anteriormente con edición no lo es en realidad. La actividad o, si se quiere, definición de editor, perfectamente tratada por la bibliografía, ha sido fijada en el siguiente marco: persona que publica por medio de la imprenta u otro procedimiento una obra, ajena por lo regular, multiplicando los ejemplares (Real Academia Española, 2014) ${ }^{1}$ y gestiona comercialmente su difusión (López Yepes, 2004). En la bibliografía se hallan diversos términos que, aunque persiguen establecer las diferencias mencionadas, cuando lo hacen, lo consiguen con dificultad: financiador, mandante, librero, distribuidor, comitente, promotor, mecenas..., todo ello sin olvidar al autor o al impresor cuando, además de su función característica, asumen la financiación de la edición.

Resulta, por tanto, necesario recurrir al momento de la génesis de la edición (ese conjunto de conjuntos de pliegos más o menos idénticos que constituirán la tirada de un libro) en el que los protagonistas van adquiriendo sus respectivos papeles y responsabilidades que, sin embargo, solo en ocasiones, quedan plasmadas por escrito en documentos de compromiso y de obligado cumplimiento para todas las partes. Se cuenta, para ese fin, con un notable corpus de contratos editoriales rescatados de los archivos de los protocolos notariales, en este caso principalmente del de Zaragoza. Pero, aún más, para comprender mejor la función del editor, que posee rasgos muy heterogéneos, es necesario establecer una aproximación a su clasificación (Rubió, 1955). ${ }^{2}$

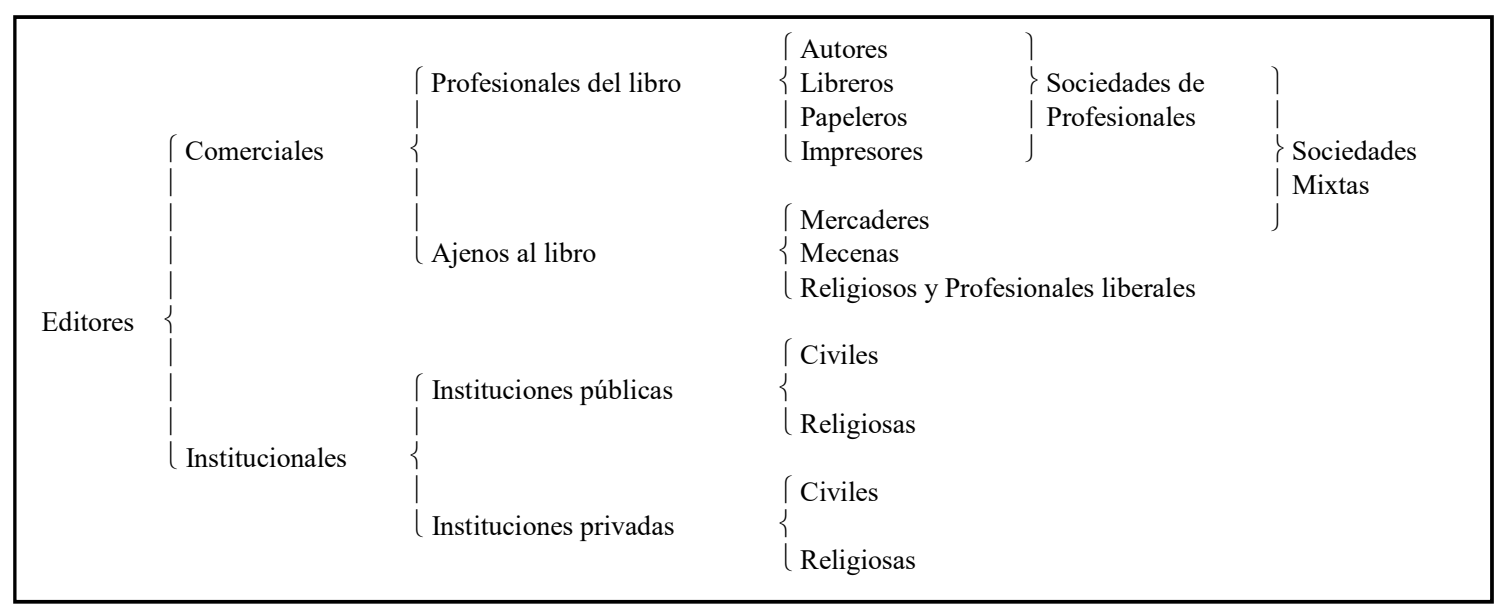

Cuadro I. Clasificación de los editores según sus actividades económicas y sociales. 
En otro lugar (Pedraza, 2008, 2015) se ha establecido el siguiente cuadro clasificatorio de los editores utilizando como criterio diferenciador principal su actividad profesional en relación con el libro y, de forma supletoria, su situación administrativa, económica o social, al que se remite.

Pero una vez establecidas, aunque sea de forma somera, primero, una casuística y, consecuentemente, una clasificación de los editores, surgen algunas preguntas: ¿la principal actividad del editor se centra con exclusividad en financiar la publicación de una obra y, si es menester, en su distribución? Y, en cualquiera de los casos, ¿su relación con el producto final es meramente de tipo económico?, o, si se quiere, ¿qué tiene que ver el editor con el resultado impreso desde las perspectivas técnica, material, formal, estética...?

Desde una posición eminentemente teórica el editor es el punto de partida de la publicación. Si hay una actividad que caracteriza al editor es decidir qué se publica, lo que define la trascendencia real de la función que desempeña. Él se compromete a dar a conocer o ampliar el número de ejemplares de una determinada obra ya publicada por él mismo o por otros. Esta decisión conlleva, de forma directa o delegada, el compromiso de arriesgar una cantidad económica para que ese compromiso se cumpla. De esta manera, el editor puede ser también, y a la vez, un autor o un impresor que desempeñará la función de editor, siempre y cuando decida publicar su obra o publicar un manuscrito u otra obra ya publicada aportando los recursos económicos (en ocasiones, también materiales y personales) para que ese compromiso se lleve a efecto. No se debe olvidar que el autor que prevé un importante beneficio de su obra editando de forma directa evita cualquier tipo de intermediación maximizando beneficios y que son muy numerosos los impresores que poseían negocios de librería anejos o no al taller tipográfico, regentados por criados de confianza.

La primera de las preguntas quedaría, así, respondida. La principal actividad de un editor es decidir qué se da a conocer, qué se publica, y costear su edición o reedición y ambas actividades van de la mano. Pero, además, a la luz de la documentación, entre las funciones del editor se incluyen una serie de intervenciones, que son independientes de su clase o tipo, que desarrolla mediante su actuación en la producción del libro desde ese momento inicial hasta el final de la misma.

\section{3 ¿QUÉ HACE UN EDITOR EN EL ANTIGUO RÉGIMEN TIPOGRÁFICO?}

Su primera actuación debería ser el hacerse con el privilegio de impresión por solicitud directa, compra, cesión o promesa de canje con un número determinado de ejemplares, una vez culminada la obra (Agulló, 1992, p. 66-67). Este hecho era preceptivo para poder iniciar la edición correspondiente con garantías de llevarla a cabo (Reyes, 2000a, nota $216 ; 2000$ b y 2001).

... Yo, dicho don Martin de Bolea, de grado etc. prometo y me obligo de traer de la villa de Madrid a mi propia costa dentro tiempo de mes y medio de oy adelante contadero y dar y entregar a vos pedro de Ybarra, librero, vezino de la ciudad de Çaragoça, un privilegio original de su magestad sellado y despachado en la forma acostumbrada de la Real Cancilleria de Aragon para que nadie sino vos dicho Pedro de Ybarra o quien vos quisieredes pueda imprimir en estos reynos de Aragon el libro llamado "Orlando determinado" que yo e compuesto y ordenado por tiempo de diez años... ${ }^{3}$

Obviamente, se podía iniciar la edición de un libro sin el privilegio correspondiente, pero en el contrato eran exigidas las responsabilidades pertinentes para cubrir los gastos en caso de no poder obtenerse y concluir el negocio en pérdidas.

Item, es concordado entre las dichas partes que en caso que se allare por el dicho Bartholome de Najera o otri por el diere el dicho libro a que se imprima en otras partes o por notario difinido o negligencia suya por hurtarle el original o quadernos impressos se imprimiere el dicho libro en otras partes que antes de haver el privilegio para hazer dicha impresion y vender dichos libros, que en tal caso, el dicho Bartholome de Najera tenga obligacion de pagar al dicho Gaspar de Tejeda mil y quatrozientos sueldos jaqueses por el danyo que el podria recebir en no haber effecto esta impresion de los dichos sietecientos libros y por hazerse aquellos en otras partes... ${ }^{4}$

Como segunda actuación debía encargar la elaboración de una copia del original, de forma que se pudiesen cumplir los preceptos legales y la edición quedase preservada ante cualquier problema que impidiese su posterior impresión; por tanto su función era doble: el uso para los fines legales establecidos y, usando una terminología actual, la de «copia de seguridad», lo que adquiere especial relevancia cuando el unicum entra dentro de la espiral comercial, resultando ser solo fundamento de la relación que se inicia entre las partes que contratan. 
... Comparescio el venerable mosen Johan Gilbert, clérigo, habitant en de la ciudat de Calatayud, el qual dixo que cumpliendo el mandato por los dichos sennores diputados a el fecho, libro en poder d'ellos el «Arbol e descendencias», siquiere "Genelogia de los reyes de Aragon» que fizo Antich de Vages y en pargamino scripto e una copia en paper escripta de aquel, suplicando a los señores diputados le mandases pagar la dicha copia... $^{5}$

Esta preservación del original adquiere verdadera importancia cuando el editor encarga una traducción de la misma o el acomodo de la obra al público para el que estima que mejor puede ir destinada. En este caso se puede producir la intervención de otros responsables (diferentes del autor) en la elaboración del texto modificándolo hasta darle la forma en la que se va a publicar. La participación de estos nuevos responsables puede llegar a propiciar nuevas atribuciones de la obra en cuestión.

... En dias pasados por los diputados predecesores nuestros vos fue dado cargo de hazer compilar y traduzir de latin en el romançe la "Coronica de Aragon», la qual haviades de dar acabada dentro tiempo de tres meses... ${ }^{6}$

Definitivamente, ante la tardanza en proceder a la traducción por parte del canónigo, se encargó la traducción a Lucio Marineo Sículo que viene siendo considerado como el autor de la obra, puesto que en ningún lugar de la obra editada se menciona como autor del original latino encargado por Alfonso $\mathrm{V}$ a Antich de Bages, que fue secretario de tres monarcas aragoneses: Alfonso V, Juan II y Fernando II.

... Por quanto por la memoria de los Reys que han sucehido en este Regno y los tiempos y fazanyas que fizieron y que fijos hovieron, los diputados predecesores nuestros tubieron por bien de haver de cobrar de Johan de Antich de Vages, fijo de micer Johan Antich de Bajes, secretario que fue del rey don Alonso de gloriosa memoria, la "genealogia y arbol de la descendencia de los dichos reyes», la qual el saco y fizo de mandamiento del dicho Rey don Alonso, y aquella havemos deliberado de impremir. E porque liebe buen estilo havemos dado cargo al reverendo prior del Sepulcro, condiputado nuestro, para que las faga ver, y reconoscer y poner lo necesario al Siculo, grant poeta, que es venido a esta ciudat, el qual a començado a entender en ello. E asi, havemos mandado dar al dicho prior para dar al sobredicho Siculo y al emprentador, y para otras cosas necesarias para el readreço de dicho «arbol e genealogia», cinquanta libras jaquesas de las quales se a ofrecido dar cuento y razon...

En consecuencia, puede decirse que puede haber ocasiones en las que el editor (en este caso una institución pública civil, por lo que la obtención del privilegio no supone ningún problema) interviene en el proceso de publicación desde momentos previos a la imprescindible relación con el impresor. En el que ha servido de ejemplo, el editor institucional interviene en esos momentos previos mediante tres actuaciones sucesivas:

1. Compra la obra manuscrita a los herederos del autor.

2. Encarga una copia para poder trabajar con ella en vías de la edición cuya modificación (traducción) persigue.

3. Encarga una traducción y selecciona al traductor: Esta traducción será la versión final que se va a publicar.

Tampoco es extraño que el editor realice correcciones de la obra especialmente en la edición de clásicos y en la reedición de obras previamente editadas por él mismo o por otros. Esta actividad es especialmente relevante cuando el editor es el propio impresor. El editor se sitúa hasta aquí en el proceso entre el autor y el impresor entre la obra y la edición aportando valores añadidos de diferente tipo:

- encargo de la elaboración de copias de trabajo lo que permite el control de la integridad de la obra, y la obtención del privilegio;

- obtención del privilegio lo que permite garantizar un beneficio mediante el monopolio de distribución;

- elaboración de correcciones o traducciones, en su caso, con objeto de ampliar la clientela potencial. Este tipo de actuaciones exigen casi siempre la intervención de especialistas que debe contratar el editor, lo que supone costes añadidos anteriores a la impresión.

Posteriormente, en su relación con el impresor, el análisis de los contratos pactados entre los editores y los impresores demuestra que los editores intervienen de forma directa o indirecta en la estructura del libro, incluso en los aspectos formales. No obstante, como los contratos pactados entre editor e impresor son pactos entre particulares, las cláusulas que los constituyen varían en función de sus intereses y necesidades y pueden ser tan variadas como posibilidades haya de acuerdo o, si se quiere, de disenso.

Se pueden encontrar, por consiguiente, numerosos aspectos, entre los que se incluyen el tipo y cuerpo, el papel, el formato, las ilustraciones que han de figurar en la obra..., que, perteneciendo esencialmente al ámbito técnico, estético, material y formal se pactan en los contratos. Muchas de estas cuestiones se pactan previamente y para poder dejarlos completamente fijados, se realiza sobre la marcha en el taller una muestra o prototipo que refleje el aspecto que debe tener un pliego del libro en cuestión. Esta muestra se entrega, en ocasiones, al notario para unirla al contrato, 
garantizar el pacto y servir de respaldo a cualquier discrepancia que pueda producirse al respecto durante el proceso de impresión o al finalizar el trabajo (Pedraza, 2001; Infantes, 2012).

En ella los contratantes (editor e impresor) pueden introducir las modificaciones pertinentes en el diseño de la página mediante la corrección manuscrita de los aspectos que deban incluirse o cambiarse, modificaciones, que, generalmente, quedan puestas de manifiesto en el articulado del contrato.

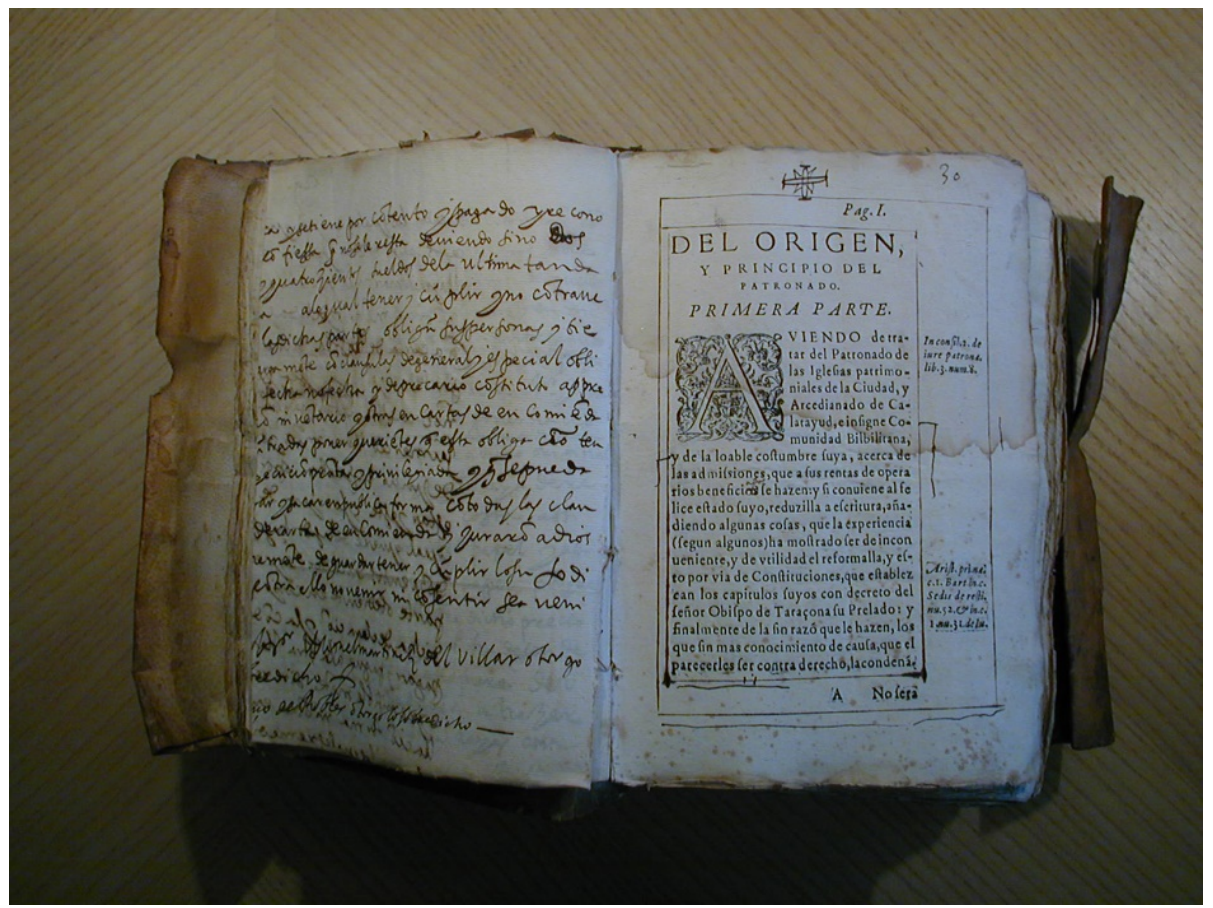

Figura 1. Muestra de impresión incluida en el contrato pactado ante el notario Diego Miguel Malo el 13 de enero de 1598.

La capitulación se pactó para realizar la impresión del El patronado, costumbres, antiguedades y varones illustres de la ciudad, arcedianado y comunidad de Calatayud escrito por Miguel Martínez del Villar.

En la muestra que sirve de ejemplo (Figura 1$)^{8}$, además de una corrección textual (beneficio $\backslash$ a/dos) se pueden observar algunas correcciones que introduce el editor (y también autor): se incluyen dos orlas lineales que enmarcan respectivamente el texto, la primera, y los marginalia, signaturas, reclamos y folio, la segunda. Este aspecto queda, además, reflejado explícitamente en la capitulación.

Y la dicha impression ha de ir con las raias conforme a la muestra que ha dado que es d'este señal [signo:

estrella de ocho puntas, cuatro de las cuales forman una cruz]. ${ }^{9}$

La muestra se confeccionó con el inicio de la obra en una sola página que se imprimió directamente sobre el papel ya plegado dejando la huella de la impresión en los tres rectos consecutivos siguientes, foliados con los números 31 , 32 y 33; y sobre el texto impreso se dibujó el signo de una estrella de ocho puntas que sirve para que la muestra no pueda ser cambiada por otra. Este proceder, permite apreciar cierto grado de desconfianza entre las partes junto con la necesidad de un aval estético, material y formal de lo que va a ser el libro acabado. Parece obvio que cuanto mayor sea la relación del editor con el mundo del libro, mayor será el conocimiento que posee sobre él y mayor será el grado de intervención que presentará el contrato. Así, el editor aporta a la edición su propia concepción sobre el libro que quiere publicar, especialmente por lo que se refiere al ámbito de la percepción estética de la página o del conjunto. ${ }^{10}$ Además, se observa, como se percibe en el ejemplo, puesto que el prototipo procede directamente de la imprenta, una intervención directa del editor (en este caso, como se ha dicho, también autor), marcando con precisión la estética de la obra en su estructura y percepción visual con una mise en page estética y tipográficamente más elaborada que la propuesta por el impresor en la muestra.

Aunque no existan muestras, el editor, con objeto de tomar el control económico, persigue supervisar el mayor número de los elementos de la imprenta que intervienen en la impresión, tanto materiales como personales.

El mayor grado de intervención de un editor (independientemente de que además tenga otras responsabilidades en la obra, como la autoría) llega hasta el extremo cuando acoge en su propia casa las herramientas de impresión con 
objeto de que el control sobre la impresión sea total. No se oculta que, de esta manera, cuando es autor de la obra, también tiene la posibilidad de hacer las correcciones en el texto que sean necesarias, pudiendo parar la prensa para introducir los cambios que considere. No obstante, el objetivo último del editor era controlar que no se imprimiesen más ejemplares que los que se habían pactado en el contrato.

... mas es tractado que el dicho Lorenzo de Robres ha de traher una prensa y lo necesario para imprimir dicha obra a la casa del dicho Jeronimo Martel y solo se le ha de dar, y el dicho Jeronimo Martel se obliga darle, todo el paper que fuere menester para dicha impresion de dichos cuerpos de libros junto a la dicha prensa... ${ }^{11}$

Así podría llegar a indicarse un pie de imprenta no necesariamente acorde con la ubicación real de la casa impresora dando lugar a pies de imprenta irreales como es el caso de la supuesta primera imprenta de Épila que inaugura la obra de Jerónimo Ximénez, Institvtionvm libri qvatvor, In Epilensi oppido: Juan Pérez de Valdivielso, 1578. El impresor de Huesca, Pérez de Valdivielso, incluye un pie de imprenta en el que localiza la impresión en Épila, lugar en el que enseñaba el autor-editor, Jerónimo Ximénez, que seguramente distribuiría también la edición (Pedraza, 2003).

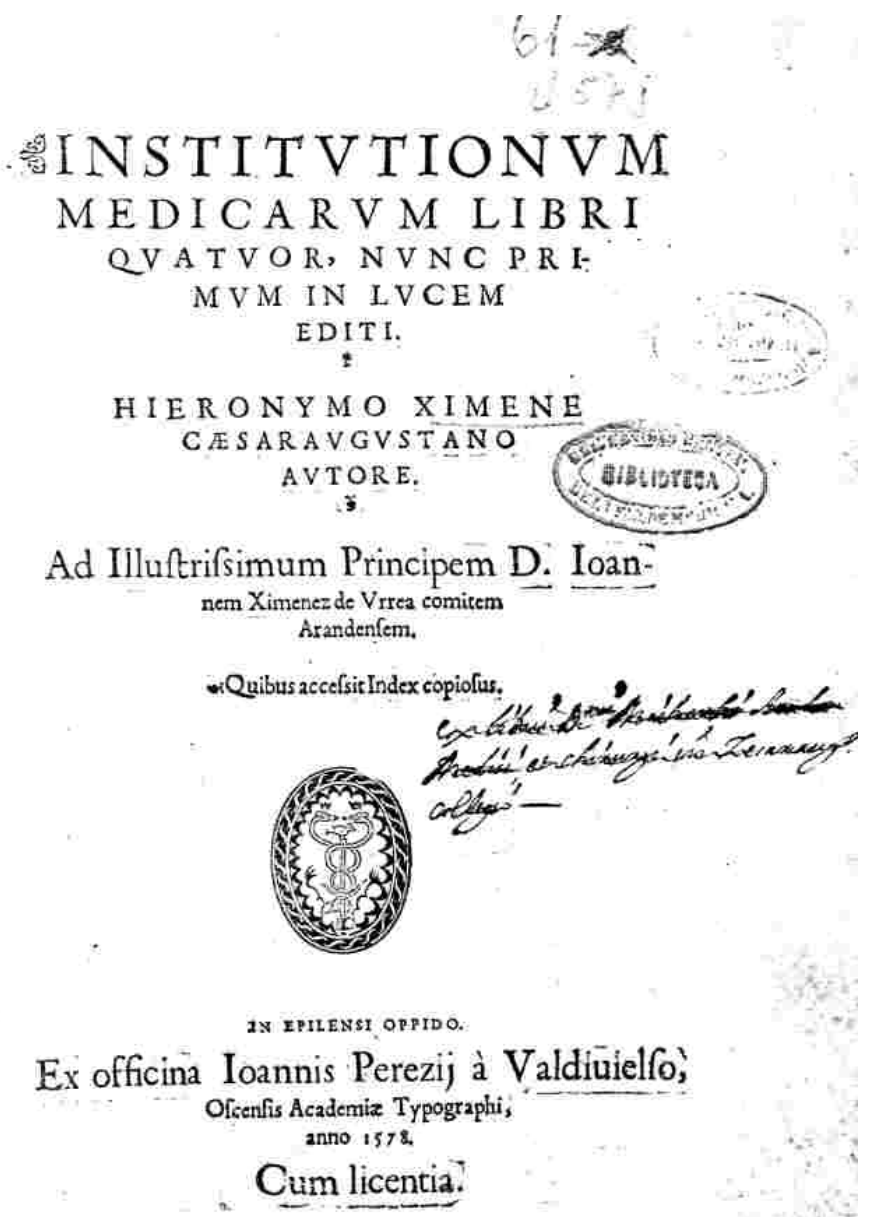

Figura 2. Jerónimo Ximénez, Institvtionvm libri qvatvor, In Epilensi oppido, Juan Pérez de Valdivielso, 1578 (Portada)

Pero sin llegar a los extremos de trasladar parte de la imprenta (cajetines, prensa, formas, tintas, lejías...), en el contrato se podían estipular múltiples condiciones que el editor marcaba y el impresor aceptaba. En el documento se acordaban principalmente: primero, las condiciones económicas; en segundo lugar, las características técnicas y formales; y quedaban de manifiesto, en tercer y último lugar, los aspectos jurídicos del mismo.

$1^{\circ}$ Entre las principales condiciones económicas que se pactan en los contratos se pueden destacar:

a) La tirada, el número de ejemplares que se debían realizar. La tirada tenía como número arquetípico el de 1.500 ejemplares, debido a ser considerado este número como la denominada «jornada castellana», esto es el número de pliegos que se podían tirar en una jornada laboral. Por esta causa suele estar entre los 750 (2 pliegos) y los 1.500 (1 pliego) (Agulló, 1992, p. 63). No obstante, se podían pactar cantidades diferentes, especialmente en el caso de ediciones de impresos menores o papeles (Agulló, 1992, p. 63), o de tiradas cortas, por ejemplo 500 ( 3 pliegos en una jornada). 
... ha de emprimir quinientos libros complidos, y ninguno ha de empremir para si ni para otro... ${ }^{12}$

b) La garantía sobre la tirada, con objeto de asegurar que no se imprimiesen más ejemplares que los contratados. El editor aclara en el contrato que firmará cada ejemplar salido de las prensas como garantía de que forma parte de la tirada de la edición contratada con el impresor.

... yo dicho Pedro de Ybarra o otra qualquiere persona por mi hallara algunos «Fueros de la Union» que se concluyeron a veynte y seys de hebrero d'este año presente año de mil quinientos noventa y quatro que no estubieren firmados de mano de mi, dicho Pedro de Ybarra, y si casso fuere hallare algunos que no estubieren firmados de mano de mi, dicho Pedro Ybarra que hayays de saber y probar vos dicho Lorenço de Robles de no estar impresso en vuestra cassa y que en este dicho casso hayays de hazer parte contra el que lo hubiera impresso valiendohos del privilegio por su excelencia el virey de Aragon... ${ }^{13}$

c) El precio por ejemplar o por unidad de producción. Con el transcurso del tiempo el precio deja de estipularse en función del ejemplar para pasar a serlo por resma impresa.

... por precio de tres florines de oro por cada raxma de paper impremida...$^{14}$

d) El coste de la producción desglosado, en ocasiones, según los gastos fijos que se producen durante la edición.

... aya de dar y pagar a los ofiçiales sus partidos dandoles lo que se acostumbra de banca cada semana y despues al fin del mes acabarles de pagar a saber:

a dos componedores a razon de a çiento y beinte quatro reales a cada uno

y a los otros dos de la prensa subira a razon de nobenta y quatro reales al mes

y a mi a nobenta y çinco reales al mes

y a mi Domingo Perez a razon de sesenta reales cada mes

y a mas d'esto a de dar para cada dia de trabajo tres sueldos y un dinero los 2 sueldos 3 para un baldres y los 6 dineros para lena y los quatro dineros para una bela... ${ }^{15}$

e) La existencia de ejemplares de cortesía para el editor no incluidos en la tirada acordada en el contrato.

... haia de dar francamente sin atar onze cuerpos de cada una de las dichas dos impresiones las ocho para los señores ocho dipputados que de presente son y las tres para Miguel Lopez escribano prinçipal de la Diputaçion, Martin de Falçes, notario extracto y Valero de Aro, su substituto... ${ }^{16}$

f) La fecha de inicio del trabajo y el tiempo en el que debían estar hechos y suministrados los ejemplares de la edición.

... los quales dichos setecientos cuerpos de libros prometemos y nos obligamos cada uno de nos por si y por el todo dar os los y entregar os los concertados y hechos libros como conviene en toda perfection dentro tiempo de treynta dias hazenderos del dia diez y ocheno del presente mes de setiembre en adelante contaderos... 17

g) El lugar en el que debían ser entregados los ejemplares producidos, que generalmente es la casa del editor, aunque, en ocasiones, se compromete el impresor a hacerlos llegar a lugares bastante alejados de la sede del taller tipográfico.

... poner los libros que assi imprimiere el dicho Bartholome de Najera a toda su costa en Medina del Campo y alli los entregue... ${ }^{18}$

h) La forma de entrega: bien sea por pliegos impresos, por un número de ejemplares concreto o por la edición íntegra.

... sea obligado de yrle entregando todos los pliegos como se fueren ymprimiendo y concertando, sin que en su poder quede ninguno...19

i) La garantía de la impresión de una segunda edición con un coste idéntico al de la primera.

... en caso que el dicho Gaspar de Tejeda quisiere hazer emprimir el dicho libro en otras partes que sea obligado de emprimirlos por mano y en la emprenta del dicho Bartholome de Najera, pues el dicho Bartholome de Najera lo imprimira por el mismo precio e coste que en otra parte el dicho Tejeda allare que se lo imprimirán... ${ }^{20}$

$2^{\circ}$ Los aspectos técnicos, estéticos y formales, que generalmente eran muy variados, se podían manifestar en el contrato o se estipulaban mediante comparación estableciendo que el libro contratado debía realizarse tomando como modelo ediciones ya publicadas por el taller, lo que condicionaba aspectos tan sustanciales como los estéticos: formato, tipografía, ilustraciones... Los más destacables y comunes son: 
a) La calidad del soporte.

... hazer la impresion de las sobredichas «Coronicas» en papel de Tiarte tan bueno como puede ser dicho papel de Tiarte... ${ }^{21}$

b) El responsable de la entrega de papel al impresor que suele ser el editor y que compra el papel como medio de control de la tirada.

... el dicho Jeronimo Martel se obliga darle, todo el paper que fuere menester para dicha impresion de dichos cuerpos de libros... ${ }^{22}$

c) El número de prensas que debían trabajar simultáneamente en la obra.

... que haran se trabaje en dos prensas en dicho libro y a razon de $1.600 \ldots^{23}$

d) El ritmo de la tirada.

... que el dicho Portonariis hara se ymprima cada dia en una prensa un pliego sin faltar ningun dia, salvo las fiestas... ${ }^{24}$

e) El cuidado y la limpieza en la impresión.

... poniendo puntos de manera que el papel no suba mas un pliego que otro, labando las formas con muy buenas lejias y hechando el principio colorado... ${ }^{25}$

... procuren los componedores que comiençen en folio y que el preçediente libro se acave con el menos blanco que ser pueda porque sera de mas policia y gracia la impresion... ${ }^{26}$

f) El aspecto y el formato, que se acuerda según una muestra que se ha entregado al notario. Sin embargo, lo más frecuente es que estos aspectos se pacten por comparación con otra obra previamente publicada, como se ha dicho.

... esto de la estampa, moldes y letra que parescen por esta muestra que se entrega con esta capitulacion bien estampado y verdadero conforme al original... ${ }^{27}$

g) Los tipos con los que se debían imprimir, cuerpo y denominación, y calidad de los mismos, lo que podría suponer una nueva fundición de tipos...

... impresos de letra de testo et sus margines y cotas de cursiva athanasia, y el inserto y latin, de la misma cursiva con sus titulos, partes, paragrafos, principio, dedicatoria y indice y al fin con todo lo que contiene dicho libro... ${ }^{28}$

... daran la letra athanasia de que tienen dada muestra para la glosa y la cursiva escolastica para el testo y estas letras para la impresion han de ser nuevas... ${ }^{29}$

h) Las ilustraciones. Generalmente, conforme avanza el tiempo la responsabilidad de aportar los recursos tipográficos para la impresión de las ilustraciones pasa del impresor al editor (Agulló, 1992, p. 72-73). bronze...

... que el escudo de las armas reales que ha de ser a contento de su paternidad y si fuere cortado en

i) Las tintas de imprenta fueron en los primeros momentos una elaboración propia de cada taller y siguieron siéndolo durante todo el periodo del antiguo régimen tipográfico.

... que daran la tinta negra muy buena y de azeite de linaza como combiene... ${ }^{31}$

j) El encargado de la corrección de las pruebas, el lugar en el que se entregan las pruebas (que no necesariamente es la imprenta), el número de pruebas y el sistema de corrección.

... hun corrector que ha de dar el dicho maestre Lax... ${ }^{32}$

k) Los preliminares literarios e iconográficos. De hecho, los preliminares iconográficos casi siempre hacen referencia al editor y parece lógico que esas ilustraciones parlantes sean propiedad de los editores más que de los impresores. ${ }^{33}$

... con una epistola dirigida al dicho Jayme Buil a cuyas costas se imprime dicho libro y con las armas de dicho Jayme Buil en el principio de cada uno de dichos libros... ${ }^{34}$ 


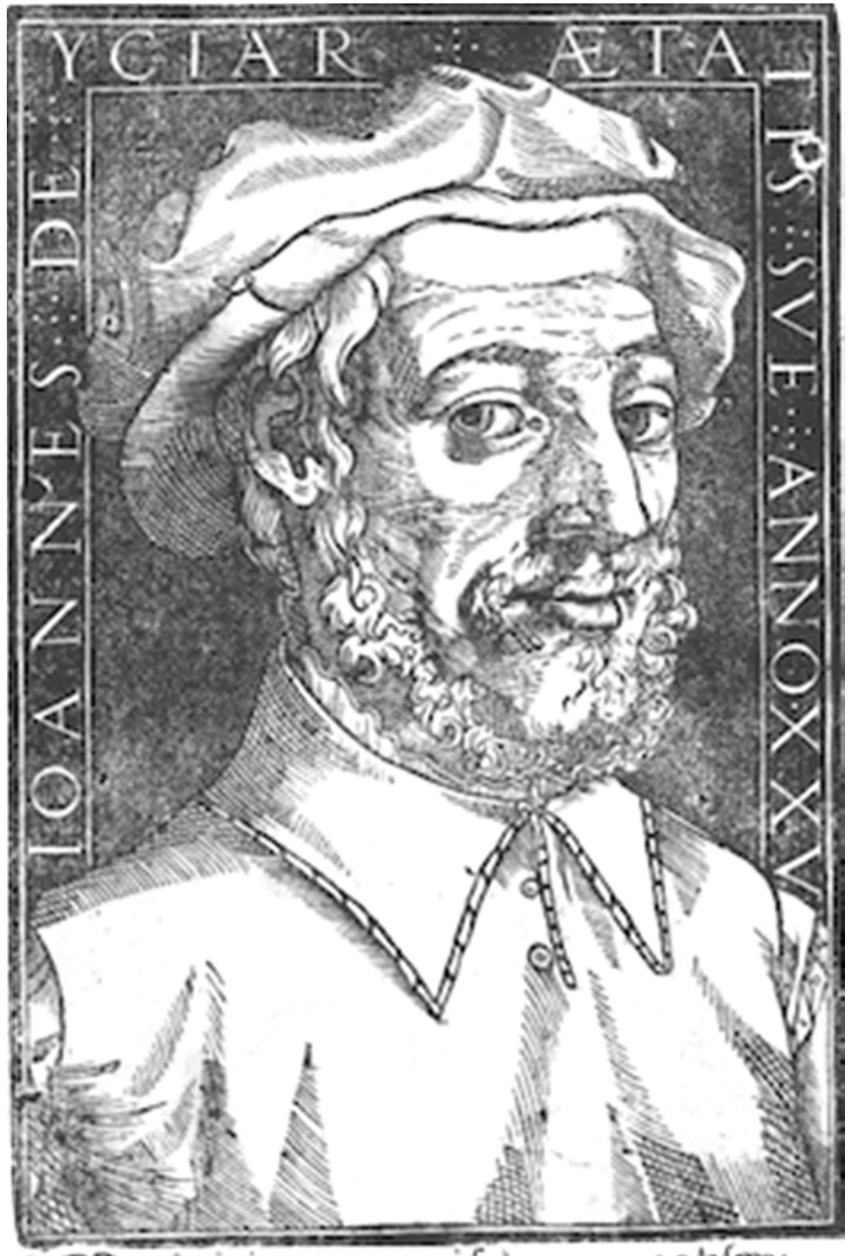

Figura 3. Retrato de Juan de Ycíar (propiedad del autor) que se incluye en las ediciones de sus obras. ${ }^{35}$

$3^{\circ}$ Finalmente, los aspectos jurídicos incluidos en el pacto eran los esenciales y comunes de cualquier contrato:

a) Las personas que contrataban.

Capitulacion y concordia tratada y asentada entre el muy reverendo fray Geronimo de Guadalupe, predicador de la orden de San Geronimo, de la una parte, y, de la otra, Domingo de Portonarys, ympresor de Su Magestad, y Luys Ganareo, mercader de libros, vezino de la dicha ciudad, en y sobre la impresion del libro que su paternidad ha compuesto sobre «El profeta Oseas»... ${ }^{36}$

b) La data crónica y tópica de realización del contrato.

... en el Monasterio de Sancta Engracia, dia de Sanct Martin a xi dias del mes de noviembre del anyo del senyor de $m$ y ccccxcviii... ${ }^{37}$

c) La inserción del privilegio.

Item, es condicion que por quanto el dicho doctor Villarino ha de traher privilegio de su magestad para dicho libro que siempre que lo tragiere ha de imprimir el dicho privilegio... ${ }^{38}$

d) Los fiadores.

... dare fiança, una o mas personas abonadas, las quales se obligaran por mi... ${ }^{39}$

e) las penas que se acostumbraba establecer por incumplimiento de cualquiera de las cláusulas del contrato.

... que por cada libro que constare averse hecho demas de los dichos, aya de pagar de pena al dicho Pedro de Ybarra, cien escudos... ${ }^{40}$

f) Los árbitros. Todo esto debía dar lugar a fricciones, para cuya solución se estipulaba en el contrato el nombramiento de personas neutrales que debían determinar la parte responsable de los problemas o desperfectos, llamados árbitros. Estos árbitros solían ser personas relacionadas con el mundo del libro, especialmente libreros, pero no siempre. 
...Item, es pactado y concordado entre las dichas partes que si por no darles papel original o pruebas o por otra causa pues sea por hecho del dicho micer Bartolome Lopez, los dichos Diego y Lorenzo de Robles dexaren de proseguir en la impression de dicho libro y perdieren algun jornal o alguna parte de aquel que en tal caso aquello aya de ser y sea llanamente conoçido por el illustre micer Martin Baptista de Lanuça, lugarteniente del señor Justicia de Aragon y que si el dicho señor micer Martin Baptista de Lanuça declare que el sobredicho impedimento ha sido por culpa y hecho del dicho micer Bartolome Lopez aquel in continenti aya y sea tenido y obligado de pagarles todo aquello que por razon de dicho impedimento declare haverseles de pagar y de la declaracion que el acerca los sobredichos haber las di-chas partes y la otra d'ellas no puedan tener ni tenga recurso alguno... ${ }^{41}$

\section{A MODO DE CONCLUSIÓN: DEMASIADAS INTERVENCIONES PARA ALGUIEN QUE NO EXISTE}

Como consecuencia, se puede llegar a la conclusión general de que el producto final de una imprenta no siempre es la consecuencia de un conjunto de decisiones de los responsables de la elaboración del impreso como producto, los impresores (al menos en su función pura de impresor). Por tanto, no parece que el libro de un taller tipográfico sea el resultado de la decisión en exclusiva del impresor, como tal, y de unos usos más o menos normalizados en cada taller a la hora de la elaboración del libro. El editor adopta numerosas decisiones sobre el libro que afectan de manera notable desde los aspectos formales -como prólogos y preliminares iconográficos...-, los materiales -como el papel, el formato o el tipo que se ha de utilizar y su cuerpo...-, los estéticos -como las ilustraciones que ha de tener y dónde se sitúan-, los técnicos - como el número de prensas, producción diaria-, hasta los textuales -elección de correctores, número de pruebas...-.

Las salvaguardas que quedan plasmadas en los contratos muestran todas estas cuestiones en las que el editor interviene, puesto que se trata de la libre decisión de dos partes sin controles externos al respecto más allá de la legislación vigente. La casuística que puede presentarse y plasmarse en la documentación es susceptible de llegar al nivel de la libre voluntad de las partes y, de hecho, así ocurre.

Se observa que con el transcurso del tiempo las diferentes posibilidades que las partes seleccionan para perfeccionar el contrato se van encorsetando dando lugar a esquemas más normalizados que deben concluir en una especie de contrato tipo que va fijando la función de cada una de las partes, también del editor, en el proceso de producción del libro.

Resulta, por consiguiente, necesario profundizar en la industria editorial y, especialmente, en la trascendencia de la participación de los editores a la hora de construir el objeto libro, porque falta todavía centrar con precisión cuáles son las causas que conducen a la toma de estas decisiones y a la evolución, si se quiere, normativización, de los contratos para comprender como se planificó una determinada edición en un determinado momento y qué influencia tienen las partes participantes en los contratos en el por qué es como es el libro de cada periodo cronológico.

Resulta evidente que desde el primer momento de la producción bibliográfica por medios mecánicos (y habría que ver si también en el caso de medios manuales) el autor confecciona una obra (un contenido) y que el impresor produce un producto múltiple (continente), pero que también existe una actividad, que solamente puede denominarse edición, que procura que un contenido y un continente múltiple confluyan en una edición y se difundan.

\section{NOTAS}

${ }^{1}$ De manera muy similar en Martínez de Sousa (1989).

2 Jordi Rubió i Balaguer estableció una clasificación de los editores en siete grupos:

1. Ediciones pagadas por eruditos o protectores de un autor o de un libro y autores que sufragan la edición de un libro propio.

2. Las obras editadas por catedrales, órdenes religiosas y corporaciones eclesiásticas.

3. Las obras editadas por impresores o por compañías de impresores.

4. Las obras editadas por compañías mixtas de impresores y mercaderes o capitalistas.

5. Las obras editadas por libreros o empresarios que contratan la labor de un impresor.

6. Las obras editadas por corporaciones oficiales o de enseñanza.

7. Las obras editadas por el impresor como labor suplementaria a los encargos recibidos.

${ }^{3}$ Martín de Bolea, caballero, domiciliado en Zaragoza, se obliga a proporcionar a Pedro de Ibarra, librero, vecino de Zaragoza, el privilegio de impresión del libro Orlando determinado que ha escrito en el plazo de un mes y medio desde el día de la fecha, a proveer de privilegio para en el caso que se deba hacer una segunda impresión y a abonar 3 sueldos por ejemplar impreso en el caso de que la inquisición impida la venta del mencionado libro. Archivo Histórico de Protocolos Notariales de Zaragoza (AHPNZ), Protocolo de Miguel Español hijo, 1578, ff. 92 v./93 v. (San Vicente, 2003, doc. 28). 
${ }^{4}$ Gaspar de Tejeda, escribano, habitante en Zaragoza, y Bartolomé de Nájera, impresor, vecino de Zaragoza, capitulan la impresión de la obra Libro de títulos y cartas mensajeras. AHPNZ, Protocolo de Bartolomé Malo, 1547, ff. 325/326 v. (Abizanda, 2015, 339-340; San Vicente 2003, doc. 6).

5 Johan Gilbert, clérigo, habitante en Calatayud, entrega la «Genealogía de los reyes de Aragón» escrita por Antich de Bages en pergamino y la copia en papel que ha hecho a los Diputados del Reino de Aragón. 1508, julio, 26, Zaragoza. Archivo de la Diputación Provincial de Zaragoza (ADPZ). Actos comunes, 1508/1509, f. 117 v. ADPZ. Actos comunes, 1508, cuaderno suelto s.f.

${ }^{6}$ Los diputados del Reino de Aragón solicitan a Lorenzo Ramón, canónigo de Calatayud, que devuelva la Crónica de Aragón [escrita por Antich de Bages] que se le entregó para traducirla al romance. 1508, febrero, 28, Zaragoza. ADPZ. Actos comunes, 1507/1508, f. 64 v. El 12 de septiembre vuelven a pedir la devolución de la copia junto con los 200 sueldos que le habían pagado por la traducción. ADPZ. Actos comunes, 1508/1509, f. 20 V.

${ }^{7}$ Los diputados del Reino de Aragón ordenan a Jaime Cariñena, arrendador y administrador de las Generalidades del Reino de Aragón, que pague al Prior del Santo Sepulcro de Calatayud 50 libras para pagar a Lucio Marineo Sículo y al impresor [Jorge Coci, por la edición de la Genealogía de los reyes de Aragón]. 1508, diciembre, 23, Zaragoza. ADPZ. Actos comunes, 1508/1509, f. 56v, 57.

8 El 13 de enero de 1598, en Zaragoza, Miguel Martínez del Villar, domiciliado en Calatayud, y Lorenzo de Robles, impresor, domiciliado en Zaragoza, capitulan la impresión de un libro titulado «El patronado, costumbres, antiguedades y varones illustres de la ciudad, arcedianado y comunidad de Calatayud» escrito por el mencionado Miguel Martínez del Villar. AHPNZ. Protocolo de Diego Miguel Malo, 1598, ff. 27/34 v.

9 El 13 de enero de 1598, en Zaragoza, Miguel Martínez del Villar, domiciliado en Calatayud, y Lorenzo de Robles, impresor, domiciliado en Zaragoza, capitulan la impresión de un libro titulado «El patronado, costumbres, antiguedades y varones illustres de la ciudad, arcedianado y comunidad de Calatayud» escrito por el mencionado Miguel Martínez del Villar. AHPNZ. Protocolo de Diego Miguel Malo, 1598, ff. 27/34 v.

${ }^{10}$ También se obra así en el mundo del manuscrito. Obligación que otorga Pero Gómez de Quenca y Francisco Cauallos al Colegio de Nuestra Señora del Orito. Madrid, 27 de enero de 1588. Archivo Histórico de Protocolos de Madrid (AHPM). Protocolo 192, ff. 20/21 (Agulló, 1992, p. $1.726)$.

11 Jerónimo Martel, infanzón, domiciliado en Zaragoza, y Lorenzo de Robles, impresor, vecino de Zaragoza, capitulan la impresión de 750 ejemplares de la «Chronologia universal». AHPNZ, Protocolo de Miguel Español, 1595, ff. 1.224/1.226 v. (San Vicente, 2003, vol. 2, doc. 88).

${ }^{12}$ Gaspar Lax, maestro mayor del Estudio de Zaragoza, y Pedro Hardouin, librero, habitante en Zaragoza, conciertan la impresión de dos libros llamados Suma expositionum in generali et in speciali y Suma silugismorum del mencionado Gaspar Lax por parte de Pedro Hardouin por 3 florines de oro la resma de papel impresa. 1528, agosto, 1, Zaragoza. AHPNZ, Protocolo de Pedro Bernuz, 1528, ff. 184/184 v.

13 Pedro de Ibarra, librero, vecino de Zaragoza, promete no servirse de una comanda de 6.000 sueldos dineros jaqueses pactada el día de la fecha con Lorenzo de Robles, impresor, vecino de Zaragoza, salvo que este imprima más ejemplares de los Fueros de la Unión de los que se han pactado o no persiga a quien pudiese imprimirlos. 1594, marzo, 21, Zaragoza. AHPNZ, Protocolo de Lorenzo de Bierge, 1594, ff. 402 v./403.

${ }^{14}$ Gaspar Lax, maestro mayor del Estudio de Zaragoza, y Pedro Hardouin, librero, habitante en Zaragoza, conciertan la impresión de dos libros llamados Suma expositionum in generali et in speciali y Suma silugismorum del mencionado Gaspar Lax por parte de Pedro Hardouin por 3 florines de oro la resma de papel impresa. 1528, agosto, 1, Zaragoza. AHPNZ, Protocolo de Pedro Bernuz, 1528, ff. 184/184 v.

${ }^{15}$ Melchor Sotes, mercader, vecino de Zaragoza, y Domingo de Portonaris, impresor, capitulan la impresión de 750 ejemplares de un libro titulado El caballero del Febo. 1579, abril, 23, Zaragoza. AHPNZ, Protocolo Sebastián Moles menor, 1579, ff. 277 v./279 v. (San Vicente, 2003, vol. 2, doc. 34).

${ }^{16}$ Gaspar Juan de la Figuera, Obispo de Albarracín, Pedro de Aragón, Miguel de Urrea, Martín de Exea y Gerónimo de Ardebines, diputados del Reino de Aragón y Domingo de Portonaris, impresor del Reino de Aragón, residente en Zaragoza, capitulan la impresión de 500 ejemplares de los Actos de Corte del Reino de Aragón y de 1.000 del Repertorio de Miguel de Molino. 1584, marzo, 16, Zaragoza. AHPNZ, Protocolo de Jerónimo Andrés, 1584, ff. 357/363.

17 Jaime Buil, notario causídico, vecino de Zaragoza, y Domingo de Portonaris, impresor, y Luis Ganareo, mercader de libros, vecinos de Zaragoza, capitulan la impresión 700 ejemplares del Modus procedendi de Miguel Ferrer. 1579, septiembre, 16, Zaragoza. AHPNZ, Protocolo de Juan Ollés, 1579 , ff. $149 \mathrm{v} . / 152 \mathrm{v}$

${ }^{18}$ Gaspar de Tejeda, escribano, habitante en Zaragoza, y Bartolomé de Nájera, impresor, vecino de Zaragoza, capitulan la impresión de la obra Libro de títulos y cartas mensajeras. 1547, junio, 21, Zaragoza. AHPNZ, Protocolo de Bartolomé Malo, 1547, ff. 325/326 v. (Abizanda, 1915 , vol. 1, p. 339-340; San Vicente, 2003, vol. 2, doc. 6).

19 Pedro de Ibarra, mercader de libros, vecino de Zaragoza, y Domingo de Portonaris, [impresor,] vecino de Zaragoza, capitulan la impresión de 1.500 ejemplares de un libro titulado Vocabulario eclesiástico. 1582, septiembre, 18, Zaragoza. AHPNZ, Protocolo de Lorenzo de Bierge, 1582, ff. $1.082 \mathrm{v} . / 1.083 \mathrm{v}$.

${ }^{20}$ Gaspar de Tejeda, escribano, habitante en Zaragoza, y Bartolomé de Nájera, impresor, vecino de Zaragoza, capitulan la impresión de la obra Libro de títulos y cartas mensajeras. 1547, junio, 21, Zaragoza. AHPNZ, Protocolo de Bartolomé Malo, 1547, ff. 325/326 v. (Abizanda, 1915, vol. 1, p. 339-340; San Vicente, 2003, vol. 2, doc. 6).

${ }^{21}$ Francisco Pérez de Pomar, castellán de Amposta, Alonso Gascón, canónigo del Sepulcro de Calatayud, Pedro d'Ixar, Antonio d'Ixar, Martín de Araus y Miguel López de Tolosa, diputados del Reino de Aragón y Juan Bautista de Negro, mercader genovés, domiciliado en Zaragoza, capitulan 750 ejemplares de la segunda edición de la primera parte de los Anales de la Corona de Aragón. 1584, diciembre, 3, Zaragoza. AHPNZ, Protocolo de Jerónimo Andrés, 1584, ff. 1.680/1.682 v.; y ADPZ, 23/8 Actos comunes 1584, cuaderno intercalado de 11 f. Notario Jerónimo Andrés.

22 Jerónimo Martel, infanzón, domiciliado en Zaragoza, y Lorenzo de Robles, impresor, vecino de Zaragoza, capitulan la impresión de 750 ejemplares de la «Chronologia universal». 1594, septiembre, 25, Zaragoza. AHPNZ, Protocolo de Miguel Español, 1595, ff. 1.224/1.226 v. (San Vicente, 2003, vol. 2, doc. 88).

23 Jerónimo de Guadalupe, religioso de la orden de San Jerónimo, y Domingo de Portonaris, impresor de su majestad, y Luis Ganareo, mercader de libros, capitulan la impresión de 1.600 ejemplares de la obra intitulada El profeta Oseas compuesta por el mencionado Jerónimo de Guadalupe. 1580, septiembre, 14, Zaragoza. AHPNZ, Protocolo de Jerónimo de Blancas, 1580, ff. 281 v./287 v. (Abizanda, 1915, vol. 1, p. 358-361; San Vicente, 2003, vol. 2, doc. 43)

${ }^{24}$ Pedro de Ibarra, mercader de libros, vecino de Zaragoza, y Domingo de Portonaris, [impresor,] vecino de Zaragoza, capitulan la impresión de 1.500 ejemplares de un libro titulado Vocabulario eclesiástico. 1582, septiembre, 18, Zaragoza. AHPNZ, Protocolo de Lorenzo de Bierge, 1582, ff. $1.082 \mathrm{v} . / 1.083 \mathrm{v}$. 
25 Melchor Sotes, mercader, Francisco Simón y Juan de la Cuesta, libreros, y Juan Soler, impresor, vecinos de Zaragoza, capitulan la impresión de 800 ejemplares de un libro titulado Historia Pontifical. 1581, junio, 20, Zaragoza. AHPNZ, Protocolo de Cristóbal Navarro padre, 1581 , ff. 723 v./725 v. Abizanda (1935, vol. 3, p. 225) lo localiza en 1586 (San Vicente, 2003, vol. 1, doc. 32 y vol. 2, doc. 45).

${ }^{26}$ Francisco Pérez de Pomar, castellán de Amposta, Alonso Gascón, canónigo del Sepulcro de Calatayud, Pedro d’Ixar, Antonio d'Ixar, Martín de Araus y Miguel López de Tolosa, diputados del Reino de Aragón y Juan Bautista de Negro, mercader genovés, domiciliado en Zaragoza, capitulan 750 ejemplares de la segunda edición de la primera parte de los Anales de la Corona de Aragón. 1584, diciembre, 3, Zaragoza. AHPNZ, Protocolo de Jerónimo Andrés, 1584, ff. 1.680/1.682 v.; y ADPZ, 23/8 Actos comunes 1584, cuaderno intercalado de 11 f. Notario Jerónimo Andrés. Canellas (1962, 79-80) menciona como fecha del contrato el mes de noviembre; Navarro Bonilla (1999, p. 101-131) menciona como folios 2.680/2.682 v. (San Vicente, 2003, vol. 2, doc. 58; Pedraza, 2004, p. 315-316).

27 Gabriel de Híjar y Jerónimo Serra, infanzones, domiciliados en Zaragoza, capitulan la impresión de La primera parte de la Monarquía Eclesiástica de fray Juan de Pineda. 1576, enero, 23, Zaragoza. AHPNZ, Protocolo de Cristóbal Navarro, 1576, ff. 90 v./92 v. (Abizanda, 1935, vol. 3, p. 225; Pedraza, 1991, doc. 17; San Vicente, 2003, vol. 2, doc. 21)

28 Miguel Martínez del Villar, domiciliado en Calatayud, y Lorenzo de Robles, impresor, domiciliado en Zaragoza, capitulan la impresión de un libro titulado El patronado, costumbres, antigüedades y varones illustres de la ciudad, arcedianado y comunidad de Calatayud escrito por el mencionado Miguel Martínez del Villar. 1598, enero, 13, Zaragoza. AHPNZ, Protocolo de Diego Miguel Malo, 1598, ff. 27/34 v. (Pedraza, 2001, p. 33-42; San Vicente, 2003, vol. 2, doc. 94)

29 Jerónimo de Guadalupe, religioso de la orden de San Jerónimo, y Domingo de Portonaris, impresor de su majestad, y Luis Ganareo, mercader de libros, capitulan la impresión de 1.600 ejemplares de la obra intitulada El profeta Oseas compuesta por el mencionado Jerónimo de Guadalupe. 1580, septiembre, 14, Zaragoza. AHPNZ, Protocolo de Jerónimo de Blancas, 1580, ff. 281 v./287 v. Abizanda, 2015, vol. 1, p. 358-361; San Vicente, 2003, vol. 2, doc. 43).

30 Jerónimo de Guadalupe, religioso de la orden de San Jerónimo, y Domingo de Portonaris, impresor de su majestad, y Luis Ganareo, mercader de libros, capitulan la impresión de 1.600 ejemplares de la obra intitulada El profeta Oseas compuesta por el mencionado Jerónimo de Guadalupe. 1580, septiembre, 14, Zaragoza. AHPNZ, Protocolo de Jerónimo de Blancas, 1580, ff. 281 v./287 v. (Abizanda, 1915, vol. 1, p. 358-361; San Vicente, 2003, vol. 2, doc. 43).

31 Jerónimo de Guadalupe, religioso de la orden de San Jerónimo, y Domingo de Portonaris, impresor de su majestad, y Luis Ganareo, mercader de libros, capitulan la impresión de 1.600 ejemplares de la obra intitulada El profeta Oseas compuesta por el mencionado Jerónimo de Guadalupe. 1580, septiembre, 14, Zaragoza. AHPNZ, Protocolo de Jerónimo de Blancas, 1580, ff. 281 v./287 v. (Abizanda, 1915, vol. 1, p. 358-361; San Vicente, 2003, vol. 2, doc. 43). Agulló (1992, p. 71) menciona en el contrato de impresión de Calendarios para la Diócesis de Toledo que se exigía que se utilizase «tinta hecha con aceite de linaza y no con aceite de comer».

32 Gaspar Lax, maestro mayor del Estudio de Zaragoza, y Pedro Hardouin, librero, habitante en Zaragoza, conciertan la impresión de dos libros llamados Suma expositionum in generali et in speciali y Suma silugismorum del mencionado Gaspar Lax por parte de Pedro Hardouin por 3 florines de oro la resma de papel impresa. 1528, agosto, 1, Zaragoza. AHPNZ, Protocolo de Pedro Bernuz, 1528, ff. 184/184 v.

33 Como ocurre con los Manuales de Palencia, en los que se indica que al principio deben ir las armas, insignias y títulos del Obispo (Pérez Pastor, 1895, p. 124-125). También en las obras de Juan de Yciar, Recopilacion subtilissima intitvlada Orthographia pratica por la qual se enseña a escreuir perfectamente..., Caragoça: Bartolomé de Nagera, 1548 (Sánchez, 1913, n. ${ }^{\circ}$ 278); Arte subtilissima por la qual se enseña a escreuir perfectamente..., Caragoca: Pedro Bernuz, 1550 (Sánchez, 1913, n. ${ }^{\circ} 301$ ); Arte svbtilissima, por la qual se enseña a escreuir perfectamente..., Caragoca: Steuan de Najara, a costas de Miguel de Çapila, 1553 (Sánchez, 1913, n. ${ }^{\circ}$ 344); Arte subtilissima por la qual se enseña e escrevir perfectamente, [Zaragoza]: a costas de Miguel de Çapila, 1555 (Sánchez, 1913, n. ${ }^{\circ}$ 377) -en ocasionas forma parte como segundo de los elementos componentes del Libro sotilissimo y prouechoso para deprender a escreuir y contar: el qual lleua la mismo orden que lleua vn maestro con su discipulo en que estan puestas las cinco reglas mas principales de guarismo y otras cosas sotiles y provechosas, Çaragoça: en casa de Esteua[n] de Nagera: a costa de Miguel de Çapila, 1555, junto con Arte breve y provechoso de cuenta catellana y arithmetica donde se muestran las cinco reglas de guarismo..., ambos con portada y signaturas propias. Sánchez $\left(1913\right.$, n. $\left.^{\circ} 384\right)$ retrasa la fecha a 1556; Libro svbtilissimo por el qual se enseña a escreuir y contar perfectamente el qual lleua la mesmo horden que lleua vn maestro con su discipulo, Caragoça: En casa de la viuda de Esteuan de Nagera, a costa de Miguel de Çapila, 1559 (Sánchez, 1913, n. ${ }^{\circ}$ 403); Libro svbtilissimo por el qual se enseña a escreuir y contar perfectamente: el qual lleua el mesmo orden que lleua vn maestro con su discipulo, Çaragoça: en casa de la biuda de Bartolomé de Nagera, a costas de Miguel de Suelues, alias Çapila, 1564 (Sánchez, 1913, n. ${ }^{\circ}$ 446); Libro subtilissimo por el qual se enseña a escreuir y contar p[er]fectamente: el qual lleua el mesmo orden que lleua vn maestro con su discipulo, [Zaragoza]: a costas de Miguel de Suelues, alias, Çapila, 1566 (Sánchez, 1913, n. ${ }^{\circ}$ 464). A éstas habría que añadir tres ediciones contrahechas posteriores y otra edición sevillana tardía de 1596. Cf. Durán (2002) que refiere la existencia de tres ediciones contrahechas siguiendo a Cotarelo (1913) y Rico y Sinobas (1903), entre otros. Sobre la edición sevillana es imprescindible Stone (1960). Véase también Pedraza (2007).

34 Jaime Buil, notario causídico, vecino de Zaragoza, y Domingo de Portonaris, impresor, y Luis Ganareo, mercader de libros, vecinos de Zaragoza, capitulan la impresión 700 ejemplares del Modus procedendi de Miguel Ferrer. 1579, septiembre, 16, Zaragoza. AHPNZ, Protocolo de Juan Ollés, 1579 , ff. 149 v./152 v.

35 Especialmente sobre las imágenes de los preliminares véase Pedraza (2016).

36 Jerónimo de Guadalupe, religioso de la orden de San Jerónimo, y Domingo de Portonaris, impresor de su majestad, y Luis Ganareo, mercader de libros, capitulan la impresión de 1.600 ejemplares de la obra intitulada El profeta Oseas compuesta por el mencionado Jerónimo de Guadalupe. 1580, septiembre, 14, Zaragoza. AHPNZ, Protocolo de Jerónimo de Blancas, 1580, ff. 281 v./287 v. (Abizanda, 1915, vol. 1, p. 358-361; San Vicente, 2003, vol. 2, doc. 43).

37 Pedro Cal, prior del Monasterio de Santa Engracia de Zaragoza, y Pablo Hurus, maestro de la imprenta, vecino de Zaragoza, capitulan la impresión de 600 Breviarios de la orden de San Jerónimo. 1498, noviembre, 13, Zaragoza. AHPNZ, Protocolo de Juan de Aguas 1498 , ff. 116 v./117 v. (Janke 1986).

38 Francisco Díaz de Villarino, doctor en medicina, domiciliado en Zaragoza, y Juan Franco, infanzón, impresor, vecino de Zaragoza, capitulan la impresión de 700 ejemplares del libro titulado Medendi canones que ha compuesto el mencionado Francisco Díaz de Villarino, por 1 dinero jaqués por cada pliego impreso. 1572, agosto, 8, Zaragoza. AHPNZ, Protocolo de Mateo Villanueva, 1572, ff. 947 v./949 v. San Vicente (2003) lo data el día 18

39 Diego de Ramellone, capellán del Arzobispo de Zaragoza, y Lorenzo de Robles, impresor, y Catalina Pérez, cónyuges, Pedro de Robles y Antonio de Robles, hermanos, impresores, vecinos de Zaragoza capitulan la impresión de un Manual de administrar Sacramentos en el Arzobispado de Zaragoza. 1598, julio, 30, Zaragoza. AHPNZ, Protocolo de Lorenzo de Bierge, 1598, ff. 829/831 v. 
40 Pedro de Ibarra, mercader de libros, vecino de Zaragoza, y Domingo de Portonaris, [impresor,] vecino de Zaragoza, capitulan la impresión de 1.500 ejemplares de un libro titulado Vocabulario eclesiástico. 1582, septiembre, 18, Zaragoza. AHPNZ, Protocolo de Lorenzo de Bierge, 1582, ff. $1.082 \mathrm{v} . / 1.083 \mathrm{v}$

41 Bartolomé López Zapata, doctor en derechos, ciudadano de Zaragoza, y Lorenzo y Diego de Robles, hermanos, impresores de libros, habitantes en Zaragoza, capitulan la impresión de la continuación de los Scholia ad Molinum de Jerónimo de Portolés. AHPNZ, protocolo de Diego Feced, 1587, ff. 1.201/1.205. (San Vicente, 2003, vol. 2, doc. 65).

\section{BIBLIOGRAFÍA}

ABIZANDA Y BROTO, M. Documentos para la historia artística y literaria de Aragón procedentes del Archivo de Protocolos de Zaragoza (siglo xvi). Zaragoza: La Editorial, 1915-1935. 3 vols.

AGULlÓ Y COBO, M. La imprenta y el comercio de libros en Madrid: siglos xvi-xvii. Tesis Univ. Complutense, 1992. 2013 [en línea]. Disponible en: <http://eprints.ucm.es/8700/> [Consulta: 21 de diciembre de 2018].

CANELlas LÓPEZ, A. Los Anales de la Corona de Aragón de Jerónimo Zurita. En: VII Congreso de Historia de la Corona de Aragón. Barcelona: Congreso de Historia de la Corona de Aragón, 1962, p. 78-80.

COTARELO Y MORI, E. Diccionario biográfico y bibliográfico de calígrafos españoles. Madrid: Tipografía de la Revista de Archivos Bibliotecas y Museos, 1913.

DELGADO CASADO, J. Un siglo de bibliografía en España. Los concursos bibliográficos de la Biblioteca Nacional (1857-1953). Madrid: Ollero y Ramos, 2001. 2 vols.

DURÁN BARCELÓ, J. Introducción. En: ICÍAR, J. Juan de Icíar, Arte subtilísima, por la cual se enseña a escribir perfectamente.... Valladolid: Junta de Castilla y León, Consejería de Educación y Cultura: Ayuntamiento de Valladolid, 2002. Reproducción facsímil de la edición de Zaragoza: Esteban de Nájera, a costas de Miguel de Çapila, 1553.

GONZÁlEZ DE AMEZÚA Y MAYO, A. Cómo se hacía un libro en nuestro Siglo de Oro. Discurso leído por el excmo. señor D. Agustín G. de Amezúa y Mayo en la solemne sesión que el Instituto de España, celebró en la Real Academia de Medicina el día 23 de abril de 1946 con ocasión de la fiesta del libro español. Madrid: Magisterio Español, 1946.

INFANTES, V. La «muestra de impresión»: un testimonio inédito de la estrategia editorial del Siglo de Oro. En: Cayuela, A.; Chartier, R. (eds.). Edición y literatura en España (siglos xvi y xvii). Zaragoza: Prensas de la Universidad de Zaragoza, 2012, p. 137-168.

JANKE, R.S. Pablo Hurus y el comercio de los libros en Zaragoza a fines del siglo xv. Príncipe de Viana. (Homenaje a José María Lacarra). Anejo, 1986, n² 2-3, p. 335-349.

LÓPEZ YEPES, J. (ed.). Diccionario enciclopédico de Ciencias de la Documentación. Madrid: Síntesis, 2004. 2 vols.

MARTÍNEZ DE SOUSA, J. Diccionario de bibliología y ciencias afines. Madrid: Fundación Germán Sánchez Ruipérez, 1989.

MÉNDEZ, A. Typographia española ò Historia de la introduccion, propagacion y progresos del arte de la imprenta en España. Madrid: Imprenta de la Viuda de D. Joachin Ibarra, 1796.

MOLL, J. Valoración de la industria editorial española del siglo xvi. En: Livre et lecture en Espagne et en France sous l'Ancien Regime. Paris: ADPF, 1981

MOLL, J. Para el estudio de la edición española del Siglo de Oro. En: Livres et libraires en Espagne et au Portugal (xvie-xxe siècles, actes du Colloque International de Bordeaux (25-27 abril 1986). Paris: Centre National de la Recherche Scientifique, 1989, p. 15-25.

MOLL, J. El impresor, el editor y el librero. En: Infantes, V.; Lopez, F. y Botrel, J.-F. (eds.), Historia de la edición y de la lectura en España 1472-1914. Madrid: Fundación Germán Sánchez Ruipérez, 2003, p. 77-82.

MOLL, J. El impresor y el librero en el Siglo de Oro. En: ASÍN REMÍREZ DE ESPARZA, F. El mundo del libro antiguo. (Curso de verano de El Escorial). Madrid: Editorial Complutense, 1996, p. 27-41. También en: Alicante: Biblioteca Virtual Miguel de Cervantes, 2013 [en línea]. Disponible en: <http://www.cervantesvirtual.com/obravisor/el-impresor-y-el-librero-en-el-siglo-de-oro/html/701b5cae-ec16-4d2c-a7a4-05720baa35e7_4.html> [Consulta: 21 de diciembre de 2018].

NAVARRO BONILLA, D. Noticias históricas en torno a la segunda edición de la primera parte de los Anales de Zurita (Juan Bautista de Negro-Simón de Portonariis, 1585). Revista de Historia Jerónimo Zurita, 1999, $\mathrm{n}^{\circ}$ 74, $\mathrm{p}$. 101-131.

ODRIOZOLA, A. La imprenta en Castilla en el siglo xv. En: Historia de la imprenta hispana. Madrid: Editora Nacional, 1982, p. 91-219.

PEDRAZA GRACIA, M.J. La imprenta de Gabriel de Hijar (Zaragoza, 1576). Zaragoza: Institución «Fernando el Católico», 1991.

PEDRAZA GRACIA, M.J. Las «muestras» en las capitulaciones para la impresión de libros: análisis de dos muestras del siglo xvi. Pliegos de bibliofilia, 2001, nº 13, p. 33-42. 
PEDRAZA GRACIA, M.J. «In Epilensi oppido»: aportación documental sobre la primera imprenta de Épila en 1578. Gutenberg-Jahrbuch, 2003, p. 139-154.

PEDRAZA GRACIA, M.J. Poder político e imprenta en el Renacimiento en la Península Ibérica: el libro y la Diputación del Reino de Aragón en los siglos xv y xvi. Cuadernos para investigación de la literatura hispánica, 2004, no 29, p. 295-320.

PEDRAZA GRACIA, M.J. Los protagonistas de la edición del Arte subtilissima: Juan de Icíar, Juan de Vingles y Pedro Bernuz. En: Icíar, J. Arte subtilisima por la cual se enseña a escribir perfectamente: edición facsímil de la de Zaragoza, Pedro Bernuz, 1550. Madrid: Universidad Complutense, 2007, p. 15-34.

PEDRAZA GRACIA, M.J. El libro español del Renacimiento: la «vida» del libro en las fuentes documentales contemporáneas. Madrid: Arco/Libros, 2008

PEDRAZA GRACIA, M.J. La función del editor en el libro del siglo xvi. Titivillus, 2015, nº 1, p. 211-226.

PEDRAZA GRACIA, M.J. Los preliminares iconográficos en el libro impreso: aproximación desde la perspectiva de la producción y la edición. En: Carvajal González, H. (ed.), Los paratextos y la edición en el libro medieval y moderno. Zaragoza: Prensas de la Universidad de Zaragoza, 2016, pp. 61-80.

PÉREZ PASTOR, C. La imprenta en Medina del Campo. Madrid: Establecimiento Tipográfico «Sucesores de Rivadeneyra», 1895.

REAL ACADEMIA ESPAÑOLA. Diccionario de la lengua española. Madrid: Real Academia, 2014 [en línea]. Disponible en: <http://www.rae.es/recursos/diccionarios/drae> [Consulta: 21 de diciembre de 2018].

REYES GÓMEZ, F. El libro en España y América: legislación y censura: siglos xv-xviii. Madrid: Arco/Libros, 2000. 2 vols.

REYES GÓMEZ, F. Licencia y privilegio en el libro español antiguo: breves notas y aclaraciones. Pliegos de bibliofilia, 2000, $\mathrm{n}^{\mathrm{o}} 15$, p. 77-78.

REYES GÓMEZ, F. Con privilegio: la exclusiva de edición del libro antiguo español. Revista general de información y documentación, 2001, vol. 11, $\mathrm{n}^{\mathrm{o}}$ 2, p. 163-200.

REYES GÓMEZ, F. Editores en busca de impresores, impresores en busca de editores en el siglo XV. En: Texto, edición y público lector en los albores de la imprenta. Valencia: Universidad de Valencia, 2014, p. $215-241$.

RICO Y SINOBAS, M. Diccionario de calígrafos españoles. Madrid: Real Academia Española (Imp. De Jaime Ratés), 1903.

RUBIÓ I BALAGUER, J. Imprempta i llibreria a Barcelona (1474-1553). Barcelona: Escola Universitària J. Rubió i Balaguer, 1986. Quaderns de Treball, 9. Originalmente en castellano como introducción de Madurell, J. M. y Rubió, J. Documentos para la historia de la imprenta y librería en Barcelona (1474-1533). Barcelona: Gremios de Editores, de Libreros y de Maestros Impresores, 1955.

SAN VICENTE PINO, A. Apuntes sobre libreros, impresores y libros localizados en Zaragoza entre 1454 y 1599. Zaragoza: Gobierno de Aragón, 2003, 2 vols.

SÁNCHEZ, J.M. Bibliografía aragonesa del siglo xvi. Madrid: Imprenta Clásica Española, 1913, 2 vols.

SIMÓN DÍAZ, J.: El libro español antiguo. $2^{\mathrm{a}}$ ed. Madrid: Ollero \& Rampos, 2000.

STONE, R. Introduction. En: ICÍAR, J. Juan de Yciar: a facsímile of the 1550 edition of Arte subtilissima, London: Oxford University Press, 1960, p. V-X. 